\title{
JPE-12-2-4
}

\section{Analysis, Design and Implementation of an Interleaved Single-Stage AC/DC ZVS Converters}

\author{
Bor-Ren $\operatorname{Lin}^{\dagger}$ and Shih-Chuan Huang* \\ ${ }^{\dagger *}$ Dept. of Electrical Eng., National Yunlin University of Science and Technology, Yunlin, Taiwan
}

\begin{abstract}
An interleaved single-stage AC/DC converter with a boost converter and an asymmetrical half-bridge topology is presented to achieve power factor correction, zero voltage switching (ZVS) and load voltage regulation. Asymmetric pulse-width modulation (PWM) is adopted to achieve ZVS turn-on for all of the switches and to increase circuit efficiency. Two ZVS half-bridge converters with interleaved PWM are connected in parallel to reduce the ripple current at input and output sides, to control the output voltage at a desired value and to achieve load current sharing. A center-tapped rectifier is adopted at the secondary side of the transformers to achieve full-wave rectification. The boost converter is operated in discontinuous conduction mode (DCM) to automatically draw a sinusoidal line current from an AC source with a high power factor and a low current distortion. Finally, a 240W converter with the proposed topology has been implemented to verify the performance and feasibility of the proposed converter.
\end{abstract}

Key words: AC-DC Converter, APWM, Power Converter

\section{INTRODUCTION}

Traditional AC/DC converters with a diode bridge rectifier followed by a bulk capacitor draw a non-sinusoidal current from the AC line which deteriorates the AC line voltage, produces radiated and conducted electromagnetic interference and reduces the input power factor. In order to meet the EN-61000-3-2 class D limit, power factor correction (PFC) has been used as a solution to improve the input power factor and to reduce the amount of harmonic current when the power level of a switching mode power supply (SMPS) is more than 75W. The most popular PFC technology is based on a front-end diode bridge rectifier followed by a boost converter. A passive power filter is the simplest solution to improve the power factor and reduce the harmonic current. However, the drawbacks of passive power filters are that they are bulky and heavy due to the size of the line frequency inductors and capacitors. Two-stage PFC topologies use an input current shaping converter in front of a DC/DC converter to achieve power factor correction and load voltage regulation. Generally two PWM controllers are needed to draw a sinusoidal line current from the utility side and to control the output voltage at a desired value. Different circuit technologies for PFC have been proposed in [1]-[10] to improve the circuit performance with a high power factor and a low harmonic current for medium and high power

Manuscript received Aug. 12, 2011; revised Jan. 18, 2012

Recommended for publication by Associate Editor Honnyong Cha.

${ }^{\dagger}$ Corresponding Author: linbr@yuntech.edu.tw

Tel: +886-5-5517456, Fax: +886-5-5312065, Nat'l Yunlin Univ. of Science and Tech.

*Dept. of Electrical Eng., National Yunlin University of Science and Technology, Taiwan

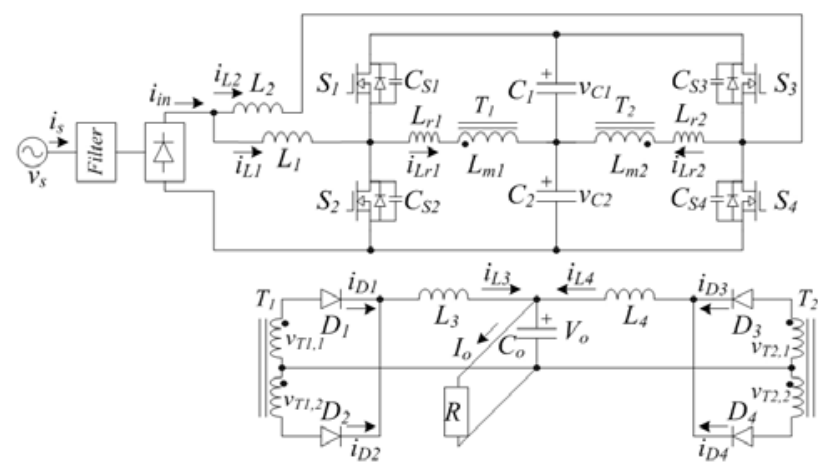

Fig. 1. Circuit configuration of the proposed converter.

applications. The main drawbacks of these topologies are that they have too many circuit components and a complex control scheme. For low power applications, a better way to improve the power factor is to combine a boost converter and a DC/DC converter by sharing their active switches to form a single-stage AC/DC converter [11]-[16] with a commercial PWM controller. However, the drawbacks of a conventional single-stage AC/DC converters are high voltage stresses on the power switches, a high DC bus voltage and hard switching on the active switches.

An interleaved single-stage AC/DC converter is proposed to achieve power factor correction, low total current harmonics, ripple current reduction at the input and output sides and zero voltage switching (ZVS) for the active switches. Therefore, the performance of the proposed converter meets the EN-61000-3-2 class D limits. There are two circuit modules in the proposed converter. There two 


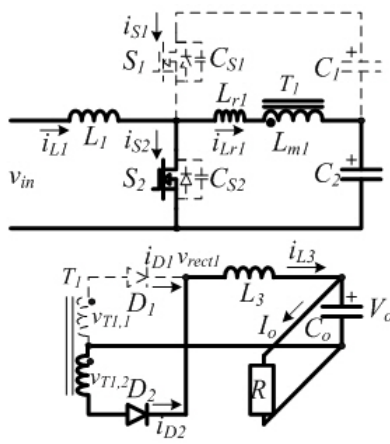

(a)

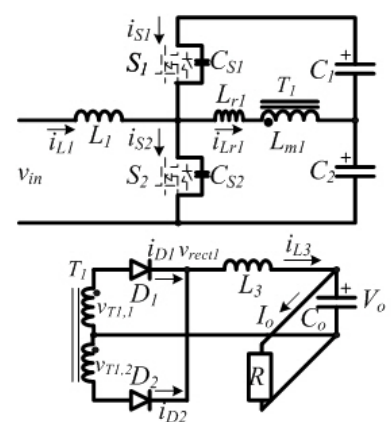

(c)

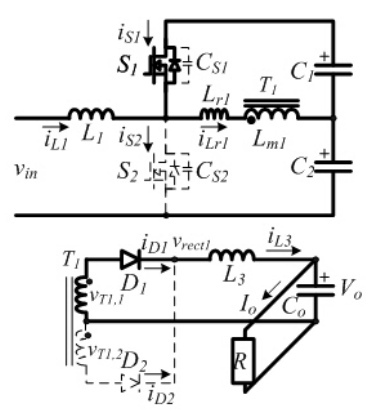

(e)

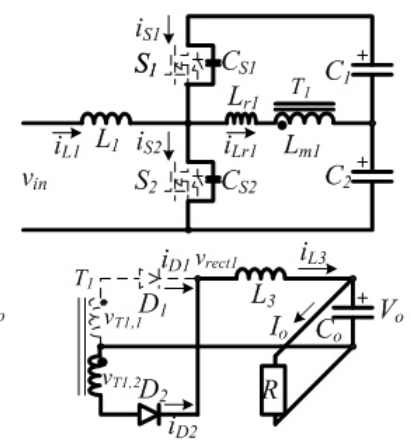

(b)

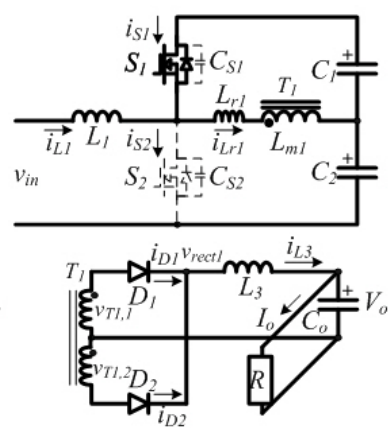

(d)

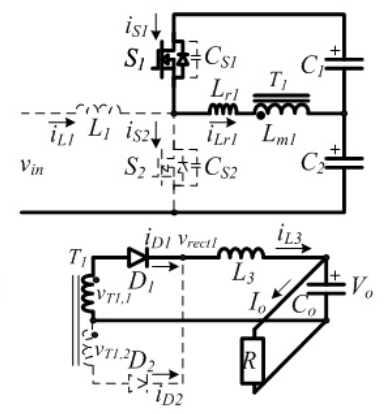

(f) modules are operated with the interleaved pulse-width modulation (PWM) scheme such that the ripple currents at the input and output sides partially cancelled each other out. Thus the conduction losses on the input and output capacitors are reduced. In each circuit module, one boost converter and one half-bridge converter with a center-tapped rectifier have the same active switches to achieve power factor correction and load voltage regulation. The boost converter is operated in the discontinuous conduction mode (DCM) to automatically achieve power factor correction. The half-bridge converter with the asymmetrical PWM scheme is operated in the continuous conduction mode (CCM) to achieve output voltage regulation and ZVS turn-on for all of the switches. The circuit configuration, operation principle and design consideration of the proposed converter are presented and discussed in detailed. Finally, experimental results, obtained from a $240 \mathrm{~W}$ laboratory prototype, are presented to demonstrate the circuit performance.

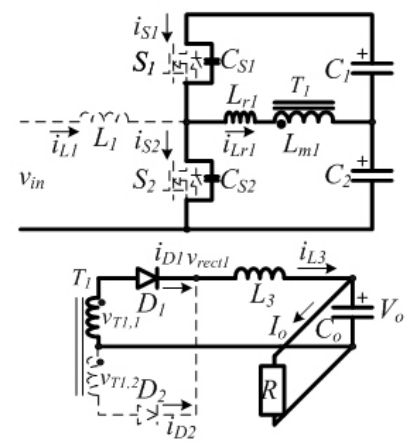

(g)

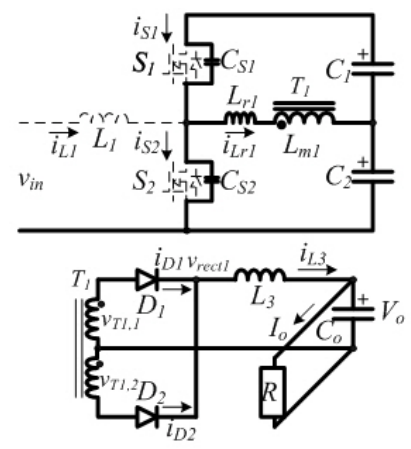

(h)

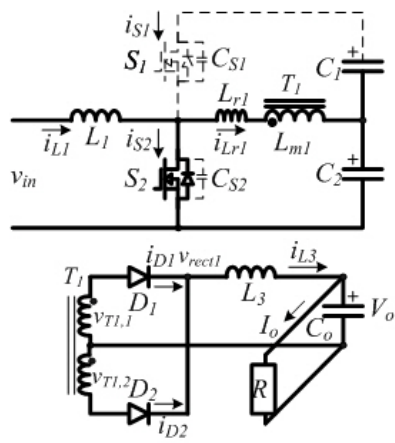

(i)

Fig. 2. Equivalent topological modes of the converter 1 operating over one switching cycle. (a) mode 1. (b) mode 2. (c) mode 3. (d) mode 4. (e) mode 5. (f) mode 6. (g) mode 7. (h)

\section{CiRCUIT CONFIGURATION}

The circuit configuration of the proposed AC/DC converter is given in Fig. 1. $v_{s}$ and $V_{o}$ are the AC input voltage and the DC output voltage, respectively. $L_{1}$ and $L_{2}$ are the input boost inductors. $C_{1}$ and $C_{2}$ are the DC bus capacitances. The DC capacitor voltages $v_{C 1}$ and $v_{C 2}$ are related to the duty ratio of the switches $S_{1} \sim S_{4} . L_{r 1}$ and $L_{r 2}$ are the resonant inductances which include the transformer leakage inductance and the external inductance. $C_{S 1} \sim C_{S 4}$ are the output capacitances of the active switches $S_{1} \sim S_{4}$, respectively. Two center-tapped rectifiers are used in the secondary side to realize full-wave rectification. Two boost type AC/DC converters, $\left(L_{1}, S_{1}, S_{2}, C_{1}\right.$ and $\left.C_{2}\right)$ and $\left(L_{2}, S_{3}\right.$, $S_{4}, C_{1}$ and $C_{2}$ ), are operated under the DCM mode and the interleaved PWM scheme to reduce ripple current and to draw a sinusoidal line current from an AC source such that an AC line current with a high power factor and a low harmonic distortion is achieved. The DC bus voltage $v_{D C}=v_{C 1}+v_{C 2}$ is higher than the peak value of the maximum AC mains voltage. The PWM signals of $S_{1}$ and $S_{2}$ are complementary to each other with a short dead time. In the same way, the PWM signals of $S_{3}$ and $S_{4}$ are also complementary. Two asymmetrical half-bridge converters, $\left(S_{1}, S_{2}, C_{1}, C_{2}, T_{1}, L_{r 1}\right.$, $\left.D_{1}, D_{2}, L_{3}, C_{o}\right)$ and $\left(S_{3}, S_{4}, C_{1}, C_{2}, T_{2}, L_{r 2}, D_{3}, D_{4}, L_{4}, C_{o}\right)$, with the interleaved PWM scheme and the continuous conduction mode (CCM) operation is also connected in parallel to reduce the ripple current at the output capacitor $C_{o}$ and to achieve load current sharing. $L_{r 1}, C_{S 1}$ and $C_{S 2}$ are resonant in the transition interval of $S_{1}$ and $S_{2}$ to reset the magnetic flux of transformer $T_{1}$ such that $S_{1}$ and $S_{2}$ can be 


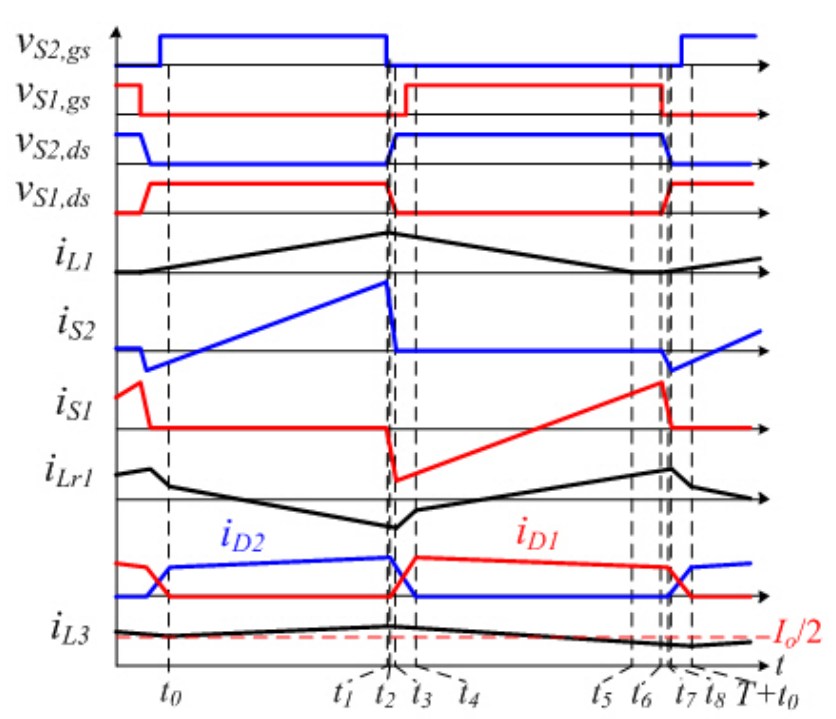

Fig. 3. Key waveforms of converter 1.

turned on under ZVS. In the same manner, $S_{3}$ and $S_{4}$ are also turned on under ZVS due to the resonant behavior of $L_{r 2}, C_{S 3}$ and $C_{S 4}$ in the transition interval of $S_{3}$ and $S_{4}$.

\section{OPERATION PRINCIPLE}

Two AC/DC ZVS converters with the interleaved PWM scheme are connected in parallel to share the load current and to reduce the ripple current. In order to simplify the system analysis, only one of the AC/DC converters is discussed in this section. The operation behavior of converter 1 over one switching cycle can be divided into nine operation modes. The equivalent topological modes, given in Fig. 2. Fig. 3, show the key waveforms of the adopted converter 1 over one switching period. In the following analysis, it is assumed that (1) $C_{1}=C_{2}>>C_{S 1}=C_{S 2}$, (2) $V_{C 1}$ and $V_{C 2}$ are constant over one switching period, (3) all of the power semiconductors are ideal, (4) $L_{r 1}<<L_{m 1}, L_{1}$ and $L_{3}$, and (5) $i_{L 3}=I_{o} / 2$ is a constant current over one switching period. Prior to $t_{0}, S_{2}$ is conducting and diodes $D_{1}$ and $D_{2}$ are both conducting. The voltage across the resonant inductor $L_{r 1}$ equals $-V_{C 2}$ such that the inductor current $i_{L r 1}$ and the diode current $i_{D 1}$ decrease. The input inductor current increases with the slope of $v_{i n} / L_{1}$.

Mode $1\left[t_{0} \leq t<t_{1}\right.$, Fig. 2(a)]: At $t_{0}$, the diode current $i_{D 1}$ decreases to zero. Thus diode $D_{1}$ is off. Since $S_{2}$ is conducting and diode $D_{2}$ is forward biased, the input inductor voltage $v_{L 1}=v_{\text {in }}$ and the output inductor voltage $v_{L 3}=V_{C 2} / n-V_{o}$, where $n=n_{p} / n_{s}$ is the turns ratio of $T_{1}$. The inductor currents $i_{L 1}, i_{L r 1}, i_{L m 1}$ and $i_{L 3}$ and the switch current $i_{S 2}$ are given as:

$$
\begin{gathered}
i_{L 1}(t)=i_{L 1}\left(t_{0}\right)+\frac{V_{i n}}{L_{1}}\left(t-t_{0}\right), \\
i_{L 3}(t) \approx i_{L 3}\left(t_{0}\right)+\frac{V_{C 2} / n-V_{o}}{L_{3}}\left(t-t_{0}\right), \\
i_{L m 1}(t) \approx i_{L m 1}\left(t_{0}\right)-\frac{V_{C 2}}{L_{m 1}}\left(t-t_{0}\right), \\
i_{L r 1}(t)=i_{L m 1}(t)-\frac{i_{L 3}(t)}{n}, i_{S 2}(t) \approx i_{L 1}(t)-i_{L r 1}(t)
\end{gathered}
$$

The inductor current $i_{L 1}$ increases linearly until switch $S_{2}$ is turned off.

Mode 2 [ $t_{1} \triangleleft<t_{2}$, Fig. 2(b)]: At $t_{1}$, switch $S_{2}$ is turned off. The positive current $i_{L 1}-i_{L r 1}$ charges the capacitor $C_{S 2}$ and discharges $C_{S 1}$. Since $C_{S 1}$ and $C_{S 2}$ are much less than $C_{1}$ and $C_{2}$, the capacitor voltages $v_{C S 1}$ and $v_{C S 2}$ can be expressed as:

$$
\begin{gathered}
v_{C S 1}(t) \approx V_{C 1}+V_{C 2}-\frac{i_{L 1}\left(t_{1}\right)-i_{L r 1}\left(t_{1}\right)}{2 C_{S 1}}\left(t-t_{1}\right), \\
v_{C S 2}(t) \approx \frac{i_{L 1}\left(t_{1}\right)-i_{L r 1}\left(t_{1}\right)}{2 C_{S 2}}\left(t-t_{1}\right)
\end{gathered}
$$

The inductor currents $i_{L 1}, i_{L r 1}$ and $i_{L 3}$ are almost constant in this mode. At $t_{2}$, the capacitor voltage $v_{C S 2}$ equals $V_{C 2}$ such that the primary voltage $v_{L m 1}=v_{T 1,1}=v_{T 1,2}=0$ and the diodes $D_{1}$ and $D_{2}$ both conduct. The time interval in this mode can be expressed as:

$$
\Delta t_{12}=t_{2}-t_{1}=\frac{2 C_{S 2} V_{C 2}}{i_{L 1}\left(t_{1}\right)-i_{L r 1}\left(t_{1}\right)}
$$

Mode 3 [ $\boldsymbol{t}_{2} \leq \boldsymbol{t}<\boldsymbol{t}_{3}$, Fig. 2(c)]: At $t_{2}$, the capacitor voltages $v_{C S 2}=V_{C 2}$ and $v_{C S 1}=V_{C 1}$. The rectifier diodes $D_{1}$ and $D_{2}$ are both conducting. The diode currents $i_{D 1}$ and $i_{D 2}$ are commutated in this mode. The diode current $i_{D 1}$ increases and $i_{D 2}$ decreases. $L_{r 1}, C_{S 1}$ and $C_{S 2}$ are resonant in this mode. Since the resonant frequency is much higher than the switching frequency, the capacitor voltages $v_{C S 1}$ and $v_{C S 2}$ are discharged and charged linearly.

$$
\begin{aligned}
& v_{C S 1}(t) \approx V_{C 1}-\frac{i_{L 1}\left(t_{2}\right)-i_{L r 1}\left(t_{2}\right)}{2 C_{S 1}}\left(t-t_{2}\right), \\
& v_{C S 2}(t) \approx V_{C 2}+\frac{i_{L 1}\left(t_{2}\right)-i_{L r 1}\left(t_{2}\right)}{2 C_{S 2}}\left(t-t_{2}\right)
\end{aligned}
$$

To ensure the ZVS turn-on of switch $S_{1}$, the capacitor voltage $v_{C S 1}$ should decrease to zero and the capacitor voltage $v_{C S 2}$ should be equal to $V_{C 1}+V_{C 2}$ before the end of this mode. The ZVS condition of $S_{1}$ is expressed as:

$$
\begin{aligned}
& \frac{1}{2} L_{1} i_{L 1}^{2}\left(t_{2}\right)+\frac{1}{2} L_{r 1} i_{L r 1}^{2}\left(t_{2}\right) \\
& >\frac{1}{2} C_{S 1} V_{C 1}^{2}+\frac{1}{2} C_{S 2}\left[\left(V_{C 1}+V_{C 2}\right)^{2}-V_{C 2}^{2}\right]
\end{aligned}
$$

This mode ends at $t_{3}$ when the capacitor voltage $v_{C S 1}=0$ and the anti-parallel diode of $S_{1}$ is conducting. The time duration of this mode is approximately expressed as:

$$
\Delta t_{23}=t_{3}-t_{2} \approx \frac{2 C_{S 1} V_{C 1}}{i_{L 1}\left(t_{2}\right)-i_{L r 1}\left(t_{2}\right)}
$$

Mode $4\left[t_{3} \leq<t_{4}\right.$, Fig. 2(d)]: At $t_{3}, v_{C S 1}=0$ and the anti-parallel diode of switch $S_{1}$ is conducting. The diodes $D_{1}$ and $D_{2}$ are still commutated in this mode. The diode current $i_{D 1}$ increases and $i_{D 2}$ decreases. The input inductor voltage $v_{L 1}=v_{i n}-V_{C 1}-V_{C 2}<0$ such that the inductor current $i_{L 1}$ decreases. Before $i_{S 1}$ is positive, $S_{1}$ must be turned on to achieve ZVS. The inductor current $i_{L r 1}$ increases with the slope of $V_{C 1} / L_{r 1}$. This mode ends at $t_{4}$ when the diode current $i_{D 2}$ is decreased to zero. The inductor current $i_{L r 1}$ increases approximately from $i_{L m 1}\left(t_{3}\right)-i_{L 3} / n$ (or $\left.i_{L m 1}\left(t_{3}\right)-I_{o} / 2 n\right)$ to $i_{L m 1}\left(t_{3}\right)+i_{L 3} / n$ (or $\left.i_{L m 1}\left(t_{3}\right)+I_{o} / 2 n\right)$. The time interval in this mode is approximately given as: 


$$
\Delta t_{34}=t_{4}-t_{3} \approx \frac{I_{o} L_{L r 1}}{n V_{C 1}}
$$

In this mode, the voltage across $T_{1}$ and $L_{r 1}$ is positive. However, the voltage $v_{\text {rect } 1}$ at the secondary side is zero. Thus the duty loss in this interval can be expressed as:

$$
D_{\text {loss }, 4}=\Delta t_{34} / T \approx \frac{I_{o} L_{L r 1}}{n V_{C 1} T}
$$

Mode $5\left[\boldsymbol{t}_{\mathbf{4}} \leq \mathbf{t}<\boldsymbol{t}_{5}\right.$, Fig. 2(e)]: At $t_{4}$, the diode current $i_{D 2}$ decreases to zero. Thus diode $D_{2}$ is off. Since $S_{1}$ is conducting and diode $D_{1}$ is forward biased, the input inductor voltage $v_{L 1}=v_{\text {in }}-V_{C 1}-V_{C 2}<0$ such that the inductor current $i_{L 1}$ decreases. The output inductor voltage $v_{L 3}=V_{C 1} / n-V_{o}$. The inductor currents $i_{L 1}, i_{L r 1}, i_{L m 1}$ and $i_{L 3}$ and switch current $i_{S 1}$ are given as:

$$
\begin{gathered}
i_{L 1}(t)=i_{L 1}\left(t_{4}\right)+\frac{v_{i n}-V_{C 1}-V_{C 2}}{L_{1}}\left(t-t_{4}\right), \\
i_{L 3}(t) \approx i_{L 3}\left(t_{4}\right)+\frac{V_{C 1} / n-V_{o}}{L_{3}}\left(t-t_{4}\right), \\
i_{L m 1}(t) \approx i_{L m 1}\left(t_{4}\right)+\frac{V_{C 1}}{L_{m 1}}\left(t-t_{4}\right), \\
i_{L r 1}(t)=i_{L m 1}(t)+\frac{i_{L 3}(t)}{n}, i_{S 1}(t) \approx i_{L r 1}(t)-i_{L 1}(t)
\end{gathered}
$$

This mode ends at $t_{5}$ when $i_{L 1}=0$.

Mode 6 [ $\boldsymbol{t}_{5} \leq \boldsymbol{t}<\boldsymbol{t}_{6}$, Fig. 2(f)]: At $t_{5}$, the input inductor current $i_{L 1}$ reaches zero. The circuit operation in this mode is the same as the operation in mode 5 except that $i_{L 1}=0$. The inductor currents $i_{L m 1}$ and $i_{L r 1}$ both increase in this mode. The switch current $i_{S 1}=i_{L r 1}$. This mode ends at $t_{6}$ when switch $S_{1}$ is off.

Mode $7\left[t_{6} \leq<<t_{7}\right.$, Fig. 2(g)]: This mode starts at $t_{6}$ when switch $S_{1}$ is turned off. The positive current $i_{L r 1}$ charges $C_{S 1}$ and discharges $C_{S 2}$. In this mode, the capacitor voltages $v_{C S 1}$ and $v_{C S 2}$ are approximately expressed as:

$$
\begin{gathered}
v_{C S 1}(t) \approx \frac{i_{L r 1}\left(t_{6}\right)}{2 C_{S 1}}\left(t-t_{6}\right), \\
v_{C S 2}(t) \approx V_{C 1}+V_{C 2}-\frac{i_{L r 1}\left(t_{6}\right)}{2 C_{S 2}}\left(t-t_{6}\right)
\end{gathered}
$$

The inductor currents $i_{L r 1}$ and $i_{L 3}$ are almost constant in this mode. At $t_{7}$, the capacitor voltage $v_{C S 2}$ equals $V_{C 2}$ such that the primary voltage $v_{L m 1}=v_{T 1,1}=v_{T 1,2}=0$ and the diodes $D_{1}$ and $D_{2}$ both conduct. The time interval in this mode can be expressed as:

$$
\Delta t_{67}=t_{7}-t_{6}=\frac{2 C_{S 2} V_{C 1}}{i_{L r 1}\left(t_{6}\right)}
$$

Mode 8 [ $\boldsymbol{t}_{7} \leq \boldsymbol{t}<\boldsymbol{t}_{\boldsymbol{8}}$, Fig. 2(h)]: At $t_{7}$, the capacitor voltages $v_{C S 2}=V_{C 2}$ and $v_{C S 1}=V_{C 1}$. The diodes $D_{1}$ and $D_{2}$ are both conducting. The diode current $i_{D 1}$ decreases and $i_{D 2}$ increases in this mode. $L_{r 1}, C_{S 1}$ and $C_{S 2}$ are resonant in this mode. The capacitor voltages $v_{C S 1}$ and $v_{C S 2}$ are approximately given as:

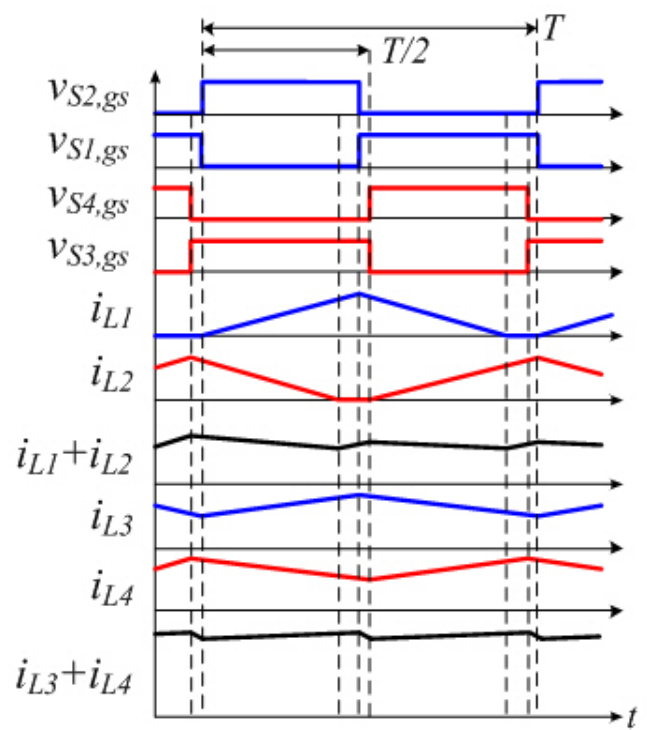

Fig. 4 Key waveforms of the proposed interleaved AC/DC converter.

$$
\begin{aligned}
& v_{C S 1}(t) \approx V_{C 1}+\frac{i_{L r 1}\left(t_{7}\right)}{2 C_{S 1}}\left(t-t_{7}\right), \\
& v_{C S 2}(t) \approx V_{C 2}-\frac{i_{L r 1}\left(t_{7}\right)}{2 C_{S 2}}\left(t-t_{7}\right)
\end{aligned}
$$

To ensure the ZVS turn-on for switch $S_{2}$, the capacitor voltage $v_{C S 2}$ should decrease to zero and the capacitor voltage $v_{C S 1}$ should be equal to $V_{C 1}+V_{C 2}$ before the end of this mode. The ZVS condition of $S_{2}$ is expressed as:

$$
\frac{1}{2} L_{r 1} i_{L r 1}^{2}\left(t_{7}\right)>\frac{1}{2} C_{S 1}\left[\left(V_{C 1}+V_{C 2}\right)^{2}-V_{C 1}^{2}\right]+\frac{1}{2} C_{S 2} V_{C 2}^{2}
$$

This mode ends at $t_{8}$ when $v_{C S 2}=0$ and the anti-parallel diode of $S_{2}$ is conducting. The time duration in this mode is approximately expressed as:

$$
\Delta t_{78}=t_{8}-t_{7} \approx \frac{2 C_{S 2} V_{C 2}}{i_{L r 1}\left(t_{7}\right)}
$$

Since the time interval of this mode is much less than the turn-on time of $S_{2}$, the input inductor current $i_{L 1}$ remains zero even if the input voltage $v_{\text {in }}$ is greater than the capacitor voltage $v_{C S 2}$.

Mode $9\left[\boldsymbol{t}_{\boldsymbol{8}} \Delta \boldsymbol{t}<\boldsymbol{T}+\boldsymbol{t}_{0}\right.$, Fig. 2(i)]: This mode begins at $t_{8}$, when $v_{C S 2}=0$ and the anti-parallel diode of switch $S_{2}$ is conducting. The diodes $D_{1}$ and $D_{2}$ are still commutated in this mode. The diode current $i_{D 1}$ decreases and $i_{D 2}$ increases. The input inductor voltage $v_{L 1}=v_{i n}>0$ such that the inductor current $i_{L 1}$ increases in this mode. The switch current $i_{S 2}=i_{L 1}-i_{L r 1}$. Before $i_{S 2}$ is positive, $S_{2}$ must be turned on to achieve ZVS. The inductor current $i_{L r 1}$ increases approximately from $i_{L m 1}\left(t_{8}\right)+i_{L 3} / n$ (or $\left.i_{L m 1}\left(t_{8}\right)+I_{o} / 2 n\right)$ to $i_{L m 1}\left(t_{8}\right)-i_{L 3} / n$ (or $\left.i_{L m 1}\left(t_{8}\right)-I_{o} / 2 n\right)$. The time interval in this mode is approximately given as:

$$
\Delta t_{08}=T-t_{8} \approx \frac{I_{o} L_{r 1}}{n V_{C 2}}
$$

The duty loss in this mode can be expressed as: 


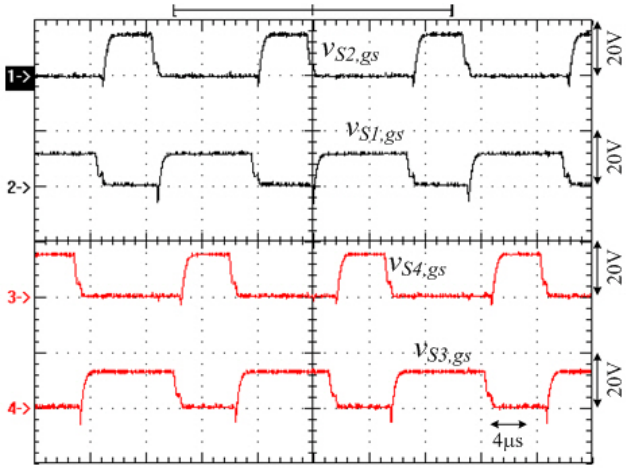

(a)

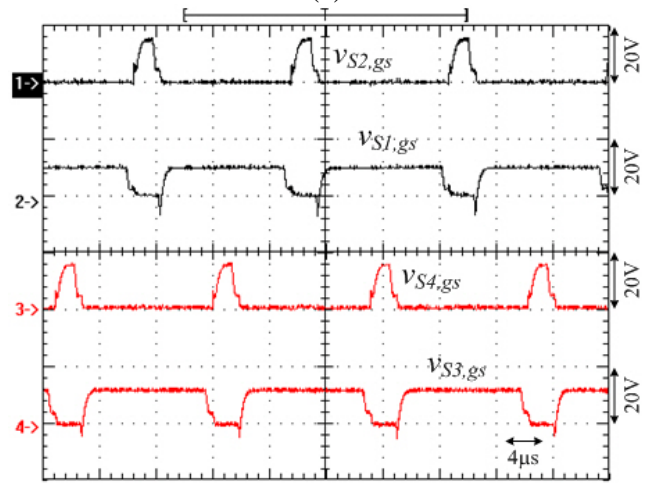

(b)

Fig. 5. Measured waveforms of the gate voltages of $S_{1} \sim S_{4}$ at full load with (a) $v_{s}=110 \mathrm{~V}_{\text {rms }}$ (b) $v_{s}=220 \mathrm{~V}_{\text {rms }}$.

$$
D_{\text {loss }, 9} \approx \frac{I_{o} L_{r 1}}{n V_{C 2} T}
$$

This mode ends at $T+t_{0}$ when the diode current $i_{D 1}$ is decreased to zero. Then the operating modes of one of the proposed converters over one switching period are completed.

In the proposed circuit, two AC/DC converters are connected in parallel to achieve the load current sharing, ripple current reduction, power factor correction and load voltage regulation. Fig. 4 shows the key waveforms of the proposed interleaved AC/DC converter. It is clear that the input and output currents are phase-shifted one-half of a switching period. The ripple currents at the input and output sides are reduced with a double switching frequency.

\section{DESIGN CONSIDERATIONS}

Since the boost converters including $\left(L_{1}, S_{1}, S_{2}, C_{1}\right.$ and $\left.C_{2}\right)$ and $\left(L_{2}, S_{3} S_{4}, C_{1}\right.$ and $\left.C_{2}\right)$ are designed in the DCM operation, the average inductor currents $i_{L 1, a v}$ and $i_{L 2, a v}$ are expressed as:

$$
\begin{aligned}
i_{L 1, a v}= & i_{L 2, a v}=\frac{T V_{s} D_{S 2}^{2}|\sin \omega t|}{2 L_{1}\left(1-\frac{V_{s}}{V_{C 1}+V_{c 2}}|\sin \omega t|\right)} \\
& \approx A|\sin \omega t|\left(1+k|\sin \omega t|+k^{2}|\sin \omega t|^{2}\right)
\end{aligned}
$$

where $A=T V_{s} D_{S 2}^{2} /\left(2 L_{1}\right), L_{1}=L_{2}$, the duty cycles of $S_{2}$ and $S_{4}$ are identical so that $D_{S 2}=D_{S 4}, k=V_{s} /\left(V_{C 1}+V_{C 2}\right), T$ is the

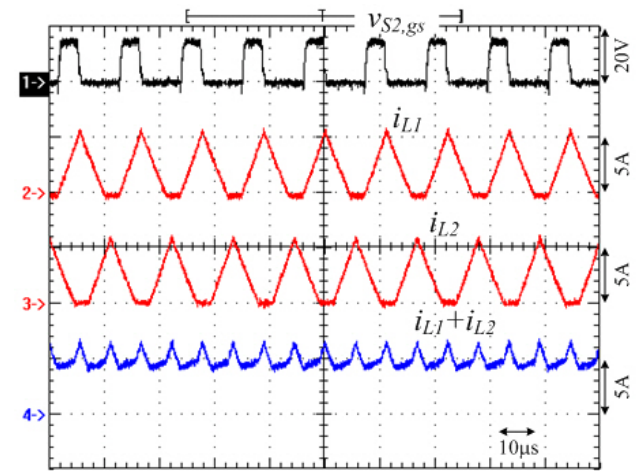

(a)

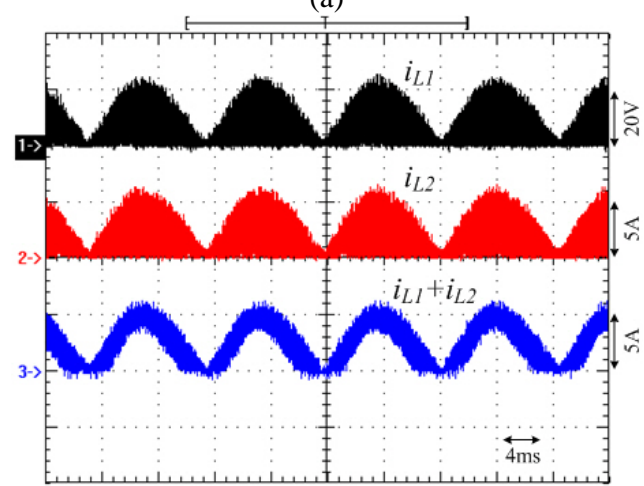

(b)

Fig. 6. Measured waveforms of input inductor currents at full load with $v_{S}=110 \mathrm{~V}_{\text {rms }}$ condition. (a) $v_{S 2, g s}, i_{L 1}, i_{L 2}, i_{L 1}+i_{L 2}$ with $10 \mu$ s time scale. (b) $i_{L 1}, i_{L 2}, i_{L 1}+i_{L 2}$ with $4 \mathrm{~ms}$ time scale.

switching period, and $V_{s}$ is the peak value of the line voltage. If the duty cycles $D_{S 1}=D_{S 3}$ are constant, the average input inductor currents $i_{L 1, a v}$ and $i_{L 2, a v}$ are rectified sinusoidal waveforms with second and third order distortions. If the voltage ratio $k$ is decreasing, the current distortion is also decreasing. The input AC line current $i_{s}$ can be expressed as:

$$
\begin{aligned}
i_{s} & \approx 2 A \sin \omega t\left(1+k|\sin \omega t|+k^{2}|\sin \omega t|^{2}\right) \\
& =2 A \sin \omega t+\text { distortion }
\end{aligned}
$$

If it is assumed the circuit efficiency is $\eta$ and the output power is $P_{o}$, then the average input power $P_{\text {in }}$ can be given as:

$$
\begin{aligned}
& P_{\text {in }}=P_{o} / \eta \\
& \approx \frac{T V_{S}^{2} D_{S 1}^{2}}{L_{1} \pi} \int_{0}^{\pi} \sin ^{2} \omega t\left(1+k|\sin \omega t|+k^{2}|\sin \omega t|^{2}\right) d \omega t
\end{aligned}
$$

The maximum constant duty cycle of $S_{1}$ and $S_{3}$ can be obtained in (20) if the input inductor $L_{1}$ and maximum load power are given as:

$$
\begin{aligned}
D_{S 1, \text { max }} & \approx \frac{1}{V_{s, \min }} \times \\
& \sqrt{\frac{\pi P_{o, \max } L_{1}}{\eta T \int_{0}^{\pi} \sin ^{2} \omega t\left(1+k|\sin \omega t|+k^{2}|\sin \omega t|^{2}\right) d \omega t}}
\end{aligned}
$$

Two asymmetrical half-bridge converters are operated in CCM operation to regulate the output voltage, share the load current and achieve ZVS turn-on for all of the active switches. 


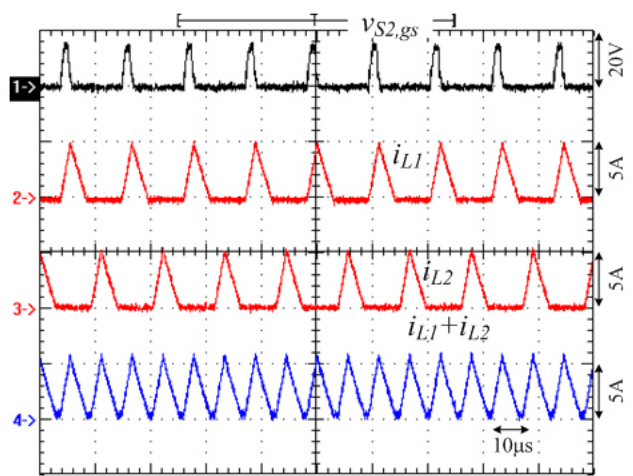

(a)

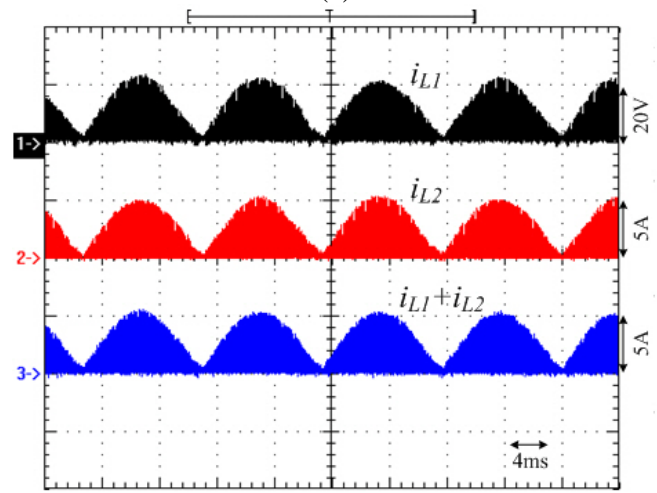

(b)

Fig. 7. Measured waveforms of input inductor currents at full load with $v_{s}=220 \mathrm{~V}_{\mathrm{rms}}$ condition. (a) $v_{S 2, g s}, i_{L 1}, i_{L 2}, i_{L 1}+i_{L 2}$ with $10 \mu$ s time scale. (b) $i_{L 1}, i_{L 2}, i_{L 1}+i_{L 2}$ with $4 \mathrm{~ms}$ time scale.

The transition intervals in modes 2-3 and 7-8 between $S_{1}$ and $S_{2}$ in converter 1 and between $S_{3}$ and $S_{4}$ in converter 2 are neglected to simplify the system analysis. When $S_{2}$ is turned on and $S_{1}$ is turned off in modes 1 and 9, the voltage across $L_{r 1}$ and $L_{m 1}$ equals $-V_{C 2}$. When $S_{1}$ is turned on and $S_{2}$ is turned off in modes 4-6, the voltage across $L_{r 1}$ and $L_{m 1}$ equals $V_{C 1}$. Based on the voltage-second balance across $L_{r 1}$ and $L_{m 1}$, the following equations can be obtained.

$$
\frac{V_{C 1}}{V_{C 2}}=\frac{D_{S 2}}{1-D_{S 2}}
$$

where $D_{S 2}$ is the duty cycle of switch $S_{2}$. In converter 1 , the output inductor voltage $v_{L 3}$ equals $V_{C 2} / n-V_{o}$ in mode $1,-V_{o}$ in mode $4, V_{C 1} / n-V_{o}$ in mode 5 , and $-V_{o}$ in mode 9 . Based on the voltage-second balance across the output inductor $L_{3}$, the output voltage $V_{o}$ can be given as:

$$
\begin{aligned}
V_{o} & =\frac{V_{C 2}}{n}\left(2 D_{S 2}-D_{\text {loss }, 9}-\frac{D_{S 2} D_{\text {loss }, 4}}{1-D_{S 2}}\right) \\
& =\frac{V_{C 2}}{n}\left(2 D_{S 2}-\frac{I_{o} L_{L r 1}}{n V_{C 2} T}-\frac{D_{S 2}}{1-D_{S 2}} \cdot \frac{I_{o} L_{L r 1}}{n V_{C 1} T}\right) \\
& =\frac{2 V_{C 2}}{n}\left(D_{S 2}-\frac{I_{o} L_{L r 1}}{n V_{C 2} T}\right)
\end{aligned}
$$

The voltage stresses of switches $S_{1} \sim S_{4}$ are approximately equal to $V_{C 1}+V_{C 2}$. The voltage stresses of the rectifier diodes $D_{1} \sim D_{4}$ are given as:

$$
v_{D 1, \text { stress }}=V_{D 3, \text { stress }} \approx \frac{2 V_{C 2}}{n}, v_{D 2, \text { stress }}=V_{D 4, \text { stress }} \approx \frac{2 V_{C 1}}{n}
$$

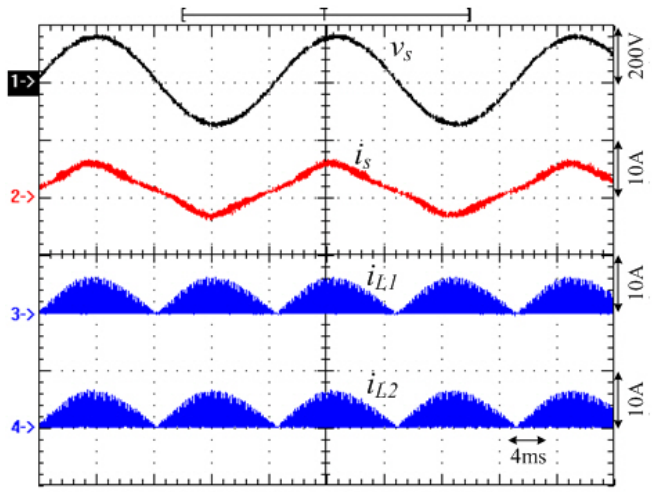

(a)

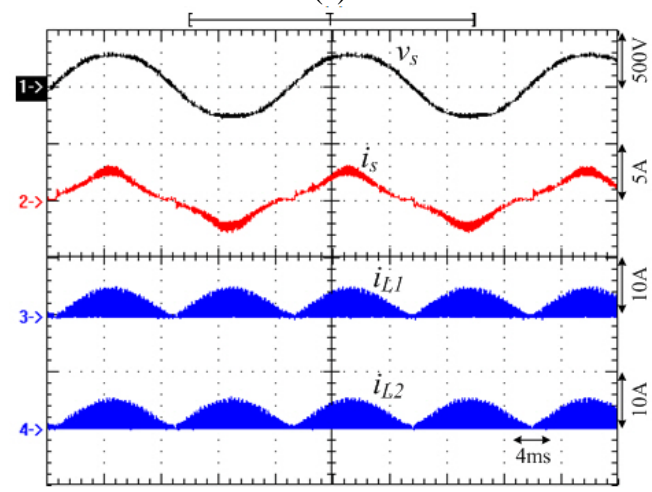

(b)

Fig. 8. Measured waveforms of $v_{S}, i_{w}, i_{L 1}$ and $i_{L 2}$ at full load with (a) $v_{s}=110 \mathrm{~V}_{\text {rms }}$ (b) $v_{s}=220 \mathrm{~V}_{\text {rms }}$.

The average and rms currents of the rectifier diodes $D_{1} \sim D_{4}$ are expressed as:

$$
\begin{gathered}
i_{D 1, a v}=i_{D 3, a v}=\frac{\left(1-D_{S 2}\right) I_{o, \max }}{2}, i_{D 2, a v}=i_{D 4, a v}=\frac{D_{S 2} I_{o, \max }}{2} \\
i_{D 1, r m s}=i_{D 3, r m s}=\frac{I_{o, \max } \sqrt{1-D_{S 2}}}{2} \\
i_{D 2, r m s}=i_{D 4, r m s}=\frac{I_{o, \max } \sqrt{D_{S 2}}}{2}
\end{gathered}
$$

The ripple current of $L_{3}$ can be obtained in mode 1 and expressed in (26).

$$
\Delta i_{L 3}=\frac{\left(V_{C 2} / n-V_{o}\right)\left(D_{S 2}-D_{\text {loss }, 9}\right) T}{L_{3}}
$$

From (16) and (26), the output inductances $L_{3}$ and $L_{4}$ can be obtained as:

$$
L_{3}=\frac{\left(V_{C 2} / n-V_{o}\right)\left(D_{S 2} T-\frac{I_{o} L_{r 1}}{n V_{C 2}}\right)}{\Delta i_{L 3}}
$$

To ensure the ZVS turn-on for switches $S_{1}$ and $S_{3}$ in mode 3, the energy stored in input inductance $L_{1}$ (or $L_{2}$ ) and the resonant inductance $L_{r 1}$ (or $L_{r 2}$ ) must be greater than the energy stored in $C_{S 1}$ and $C_{S 2}$.

$$
\begin{aligned}
& \frac{1}{2} L_{1} i_{L 1}^{2}\left(t_{2}\right)+\frac{1}{2} L_{r 1} i_{L r 1}^{2}\left(t_{2}\right) \\
& >\frac{1}{2} C_{S 1} V_{C 1}^{2}+\frac{1}{2} C_{S 2}\left[\left(V_{C 1}+V_{C 2}\right)^{2}-V_{C 2}^{2}\right]
\end{aligned}
$$




\section{TABLE I}

Measured Power Factor, Total Harmonic Distortion and Circuit EFFiciency at DifFERENT LOADS AND Line Voltages

\begin{tabular}{|c|c|c|c|c|c|}
\hline \multirow{3}{*}{$v_{s}=110 \mathrm{~V}_{\mathrm{rm}}$} & Load Power & $60 \mathrm{~W}$ & $120 \mathrm{~W}$ & $180 \mathrm{~W}$ & $240 \mathrm{~W}$ \\
\cline { 2 - 6 } & Power Factor & 0.94 & 0.958 & 0.973 & 0.986 \\
\cline { 2 - 6 } & THD & $36.3 \%$ & $30 \%$ & $23.7 \%$ & $16.9 \%$ \\
\cline { 2 - 6 } & Efficiency & $83.1 \%$ & $85.5 \%$ & $86.7 \%$ & $88.3 \%$ \\
\hline \multirow{3}{*}{$v_{s}=220 \mathrm{~V}_{\mathrm{rm}}$} & Power Factor & 0.932 & 0.952 & 0.967 & 0.975 \\
\cline { 2 - 6 } & THD & $38.8 \%$ & $32.1 \%$ & $26.3 \%$ & $22.7 \%$ \\
\cline { 2 - 6 } & Efficiency & $84.3 \%$ & $85.9 \%$ & $88.1 \%$ & $90.1 \%$ \\
\hline
\end{tabular}

In the same manner, the ZVS condition of $S_{2}$ and $S_{4}$ in mode 8 can be obtained as:

$$
\frac{1}{2} L_{r 1} i_{L r 1}^{2}\left(t_{7}\right)>\frac{1}{2} C_{S 1}\left[\left(V_{C 1}+V_{C 2}\right)^{2}-V_{C 1}^{2}\right]+\frac{1}{2} C_{S 2} V_{C 2}^{2}
$$

From (28) and (29), it can be observed that the ZVS condition of $S_{1}$ and $S_{3}$ is easier to meet than the ZVS condition of $S_{2}$ and $S_{4}$. This is because the boost is operated in DCM and the half-bridge converter is operated in CCM. From (21) and (22), the voltage conversion ratio between the output voltage and the input voltage can be expressed as:

$$
\begin{aligned}
\frac{V_{o}}{V_{s}} & =\frac{V_{o}}{V_{C 2}} \times \frac{V_{C 2}}{V_{C 1}+V_{C 2}} \times \frac{V_{C 1}+V_{C 2}}{V_{s}} \\
& >\frac{2}{n}\left(D_{S 2}-\frac{I_{o} L_{L r 1}}{n V_{C 2} T}\right) \times\left(1-D_{S 2}\right) \times \frac{1}{1-D_{S 2}} \\
& \approx \frac{2}{n}\left(D_{S 2}-\frac{I_{o} L_{L r 1}}{n V_{C 2} T}\right)
\end{aligned}
$$

\section{EXPERIMENTAL RESULTS}

The performance and effectiveness of the proposed converter were verified through experimental results. The circuit parameters of the adopted prototype circuit are $v_{\mathrm{s}}=90 \mathrm{~V}_{\mathrm{rms}} \sim 240 \mathrm{~V}_{\mathrm{rms}}, \quad V_{o}=24 \mathrm{~V}, \quad P_{o}=240 \mathrm{~W}, f=80 \mathrm{kHz}$, $L_{m 1}=L_{m 2}=130 \mu \mathrm{H}, \quad C_{1}=C_{2}=2.2 \mu \mathrm{F}, \quad L_{1}=L_{2}=100 \mu \mathrm{H}$, $L_{3}=L_{4}=180 \mu \mathrm{H}, n_{p} / n_{s}=24 / 5, S_{1} \sim S_{4}$ : IRFP460 and $D_{1} \sim D_{4}$ : BYV42E. A type 2 voltage controller based on a TL431 and an optocoupler PC817 is used to regulate the duty cycle of the power switches. A voltage mode PWM IC TL494 is used to generate two interleaved PWM signals. A gate drive IC L6384 is used to generate the four gate signals of $S_{1} \sim S_{4}$ with a proper dead time. Fig. 5 gives the measured results of the gate voltages of $S_{1} \sim S_{4}$ under a full load and low and high line voltage. It is clear that the PWM signals of $S_{1}$ and $S_{2}$ are phase-shifted with one-half of a switching period with respective to the PWM signals of $S_{3}$ and $S_{4}$. Fig. 6(a) gives the measured gate voltage $v_{S 2, g s}$, input inductor currents $i_{L 1}$ and $i_{L 2}$ and the resultant input current $i_{L 1}+i_{L 2}$ under a full load and low line voltage. The inductor currents $i_{L 1}$ and $i_{L 2}$ are phase-shifted and the resultant input current $i_{L 1}+i_{L 2}$ has less ripple current than $i_{L 1}$ and $i_{L 2}$. The measured waveforms of the input inductor currents $i_{L 1}$ and $i_{L 2}$ and the resultant input current $i_{L 1}+i_{L 2}$ under a full load and low line voltage with a $4 \mathrm{~ms}$ time scale, are shown in Fig. 6(b). The resultant input current $i_{L 1}+i_{L 2}$ is a continuous conduction mode with less ripple current. In the same manner, Fig. 7 shows the

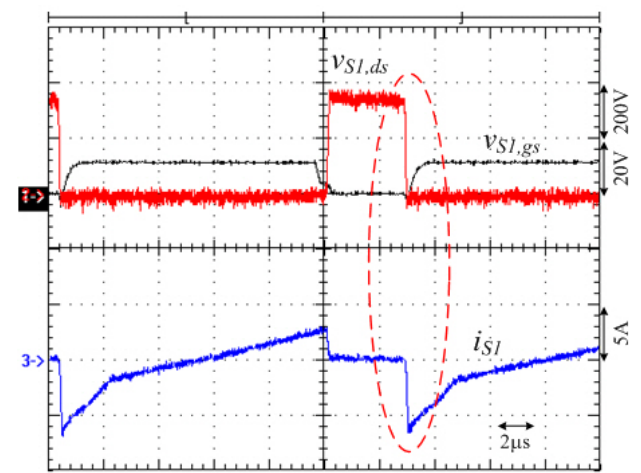

(a)

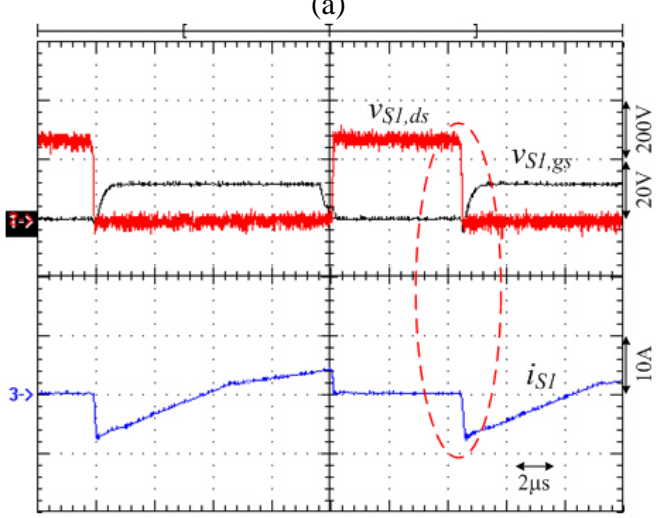

(b)

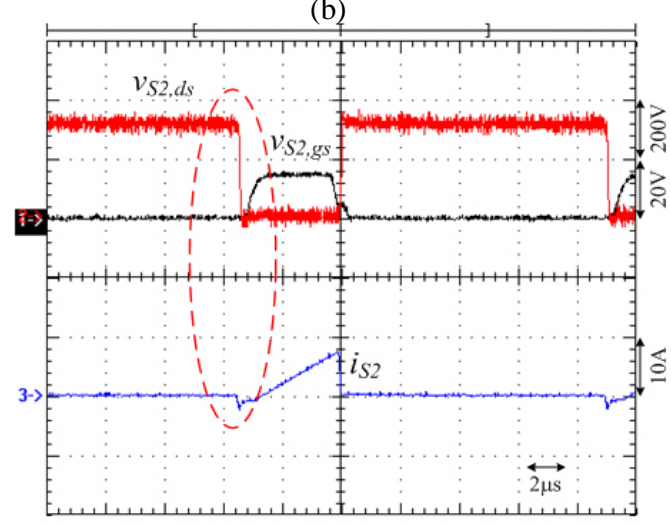

(c)

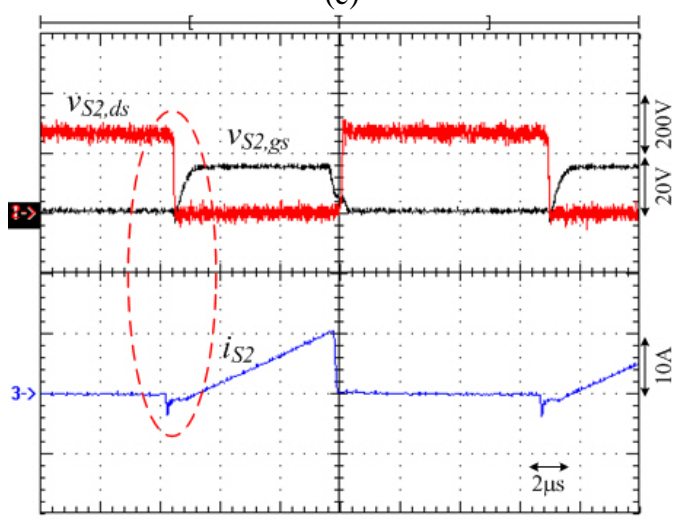

(d)

Fig. 9 Measured waveforms of gate voltage, drain voltage and drain current at $v_{S}=110 \mathrm{~V}_{\text {rms }}$ condition (a) $v_{S 1, g s}, v_{S 1, d s}$ and $i_{S 1}$ at $30 \%$ load (b) $v_{S 1, g s}, v_{S 1, d s}$ and $i_{S 1}$ at $100 \%$ load (c) $v_{S 2, g s}, v_{S 2, d s}$ and $i_{S 2}$ at $30 \%$ load (d) $v_{S 2, g s}, v_{S 2, d s}$ and $i_{S 2}$ at $100 \%$ load. 


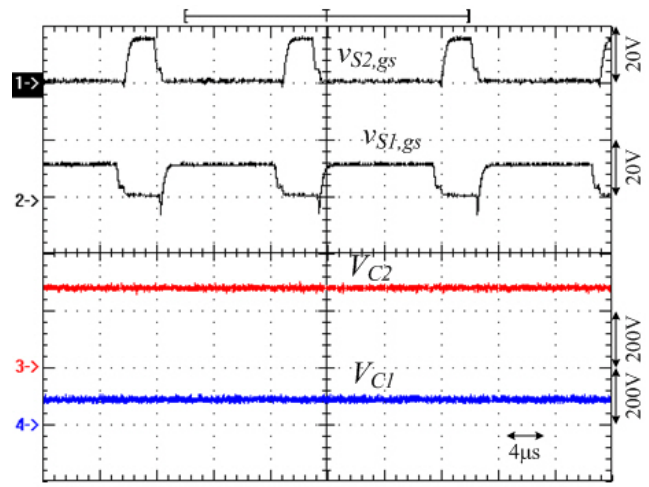

(a)

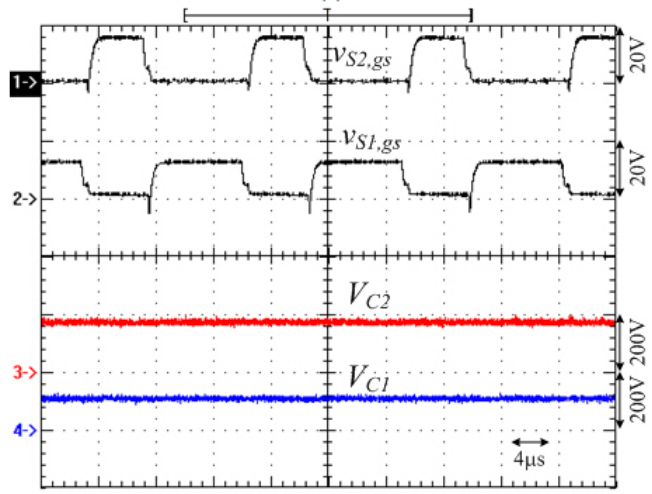

(b)

Fig. 10. Measured waveforms of $v_{S 1, g s}, v_{S 2, g s}, V_{C 1}$ and $V_{C 2}$ at $v_{s}=110 \mathrm{~V}_{\text {rms }}$ condition (a) $30 \%$ load (b) $100 \%$ load.

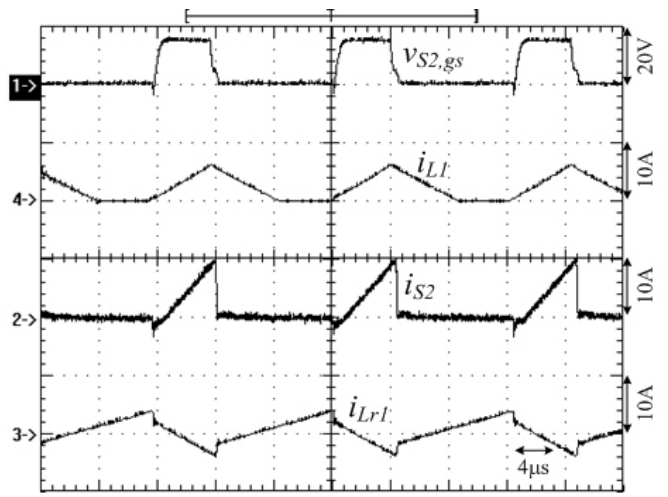

Fig. 11. Measured waveforms of $v_{S 2, g s}, i_{L 1}, i_{S 2}$ and $i_{L r 1}$ at full load and $v_{s}=110 \mathrm{~V}_{\text {rms }}$ condition.

measured results of $v_{S 2, g s}, i_{L 1}, i_{L 2}$ and $i_{L 1}+i_{L 2}$ under a full load and with $v_{s}=220 \mathrm{~V}_{\mathrm{rms}}$. Fig. 8 illustrates the measured waveforms of the line voltage, line current and input inductor currents under a full load and low and high line voltage. The line current is in phase with a line voltage with a high power factor and a low harmonic current. The measured power factor, total harmonic distortion and circuit efficiency under different load and line voltages are shown in Table 1. Fig. 9 shows the measured waveforms of the gate voltage, drain voltage and drain current of switches $S_{1}$ and $S_{2}$ at 30\% load and $100 \%$ load with $v_{s}=110 \mathrm{~V}_{\text {rms }}$. The drain voltages $v_{S 1, d s}$ and $v_{S 2, d s}$ have been decreased to zero before switches $S_{1}$ and $S_{2}$ are turned on. Therefore, the ZVS turn-on of $S_{1}$ and $S_{2}$ are realized. In the same manner, switches $S_{3}$ and $S_{4}$ are also turned on under ZVS. Fig. 10 shows the measured waveforms

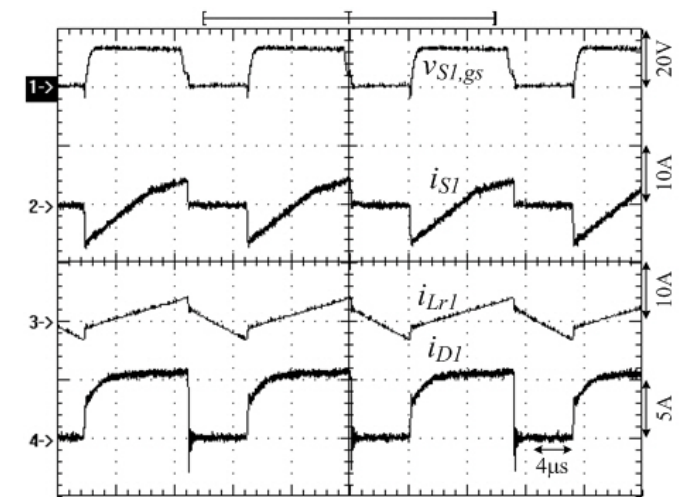

Fig. 12. Measured results of $v_{S 1, g s}, i_{S 1}, i_{L r 1}$ and $i_{D 1}$ at full load and $v_{s}=110 \mathrm{~V}_{\text {rms }}$ condition.

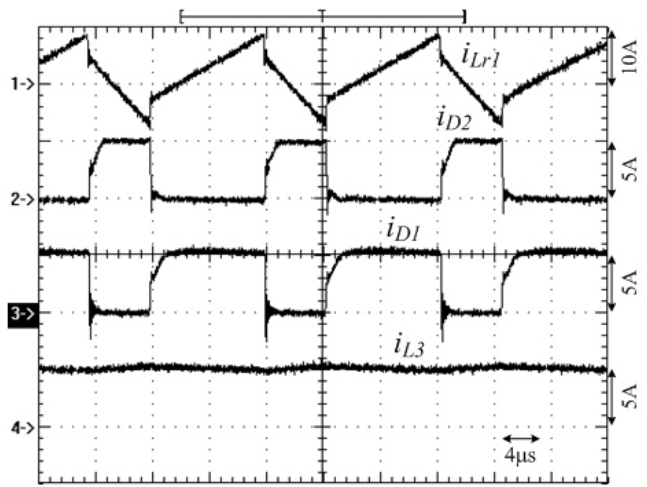

Fig. 13. Measured waveforms of $i_{L r 1}, i_{D 1}, i_{D 2}$ and $i_{L 3}$ at full load and $v_{s}=110 \mathrm{~V}_{\text {rms }}$ condition.

of the gate voltages $v_{S 1, g s}$ and $v_{S 2, g s}$ and the DC bus voltages $V_{C 1}$ and $V_{C 2}$ under a light load (30\%) and a full load (100\%) with $v_{s}=110 \mathrm{~V}_{\text {rms }}$. The capacitor voltages $V_{C 1}$ and $V_{C 2}$ are related to the duty cycle of switch $S_{2}$. Fig. 11 gives the measured waveforms of the gate voltage $v_{S 2, g s}$, input inductor current $i_{L 1}$, switch current $i_{S 2}$ and inductor current $i_{L r 1}$ under a full load with $v_{s}=110 \mathrm{~V}_{\mathrm{rms}}$. When switch $S_{2}$ is in the on state, $i_{S 2}=i_{L 1}-i_{L r 1}$. Fig. 12 shows the measured results of the gate voltage $v_{S 1, g s}$, switch current $i_{S 1}$, inductor current $i_{L r 1}$ and diode current $i_{D 1}$ under a full load with $v_{s}=110 \mathrm{~V}_{\mathrm{rms}}$. When switch $S_{1}$ is on, the primary voltage of $T_{1}$ is positive and the rectifier diode $D_{1}$ is forward biased. The switch current $i_{S 1}=i_{L r 1}-i_{L 1}$. Fig. 13 shows the measured waveforms of the inductor current $i_{L r 1}$, the rectifier diode currents $i_{D 1}$ and $i_{D 2}$ and the output inductor current $i_{L 3}$ under a full load with $v_{s}=110 \mathrm{~V}_{\text {rms }}$. When $S_{1}$ is turned on, the primary current $i_{L r 1}$ increases and the diode $D_{1}$ is forward biased. If switch $S_{2}$ is on, the primary current $i_{L r 1}$ decreases and the diode $D_{2}$ is forward biased. Fig. 14 gives the measured waveforms of the output inductor currents $i_{L 3}$ and $i_{L 4}$ and the resultant output current $i_{L 3}+i_{L 4}$ at $30 \%$ and $100 \%$ loads with $v_{s}=110 \mathrm{~V}_{\text {rms }}$. The ripple currents on the output inductors $L_{3}$ and $L_{4}$ are partially cancelled by each other. Therefore, the ripple current of $i_{L 3}+i_{L 4}$ is reduced.

\section{CONCLUSION}

A parallel AC/DC converter is presented in this paper to achieve the advantages of ZVS turn-on of all of the switches, 


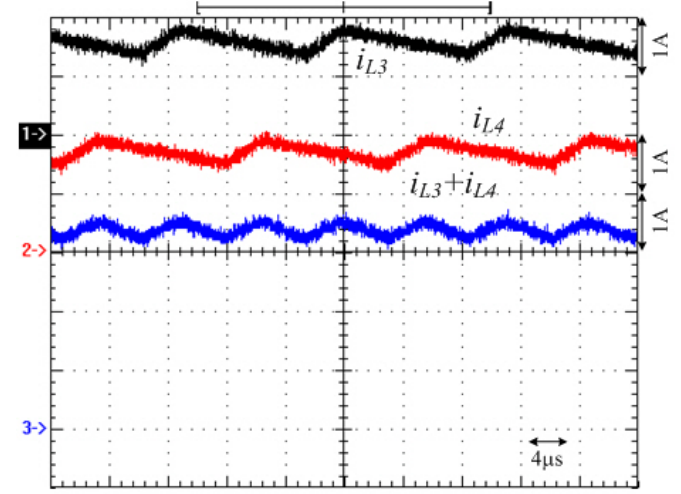

(a)

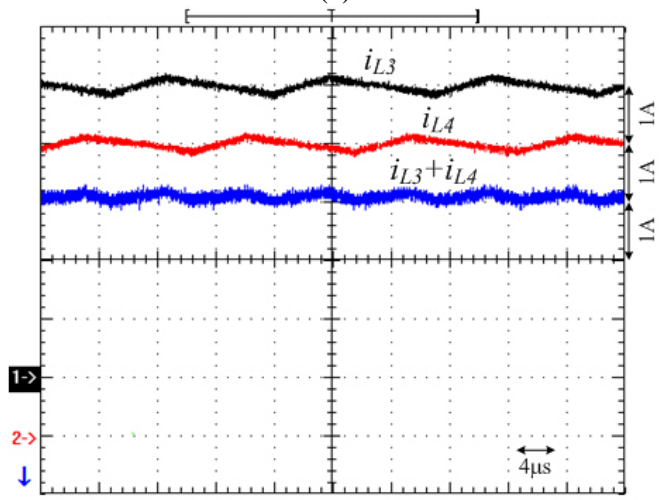

(b)

Fig. 14. Measured waveforms of $i_{L 3}, i_{L 4}$ and $i_{L 3}+i_{L 4}$ at $v_{s}=110 V_{\text {rms }}$ condition (a) 30\% load (b) $100 \%$ load.

low switching losses, a high power factor, a low total harmonic distortion of the line current, load current sharing, and ripple current reduction at the input and output sides. The input boost converter is operated under DCM operation to draw a sinusoidal line current from an AC source. Asymmetrical half-bridge converters with the interleaved PWM scheme are adopted to achieve ZVS turn-on for all of the active switches and to reduce the output ripple current. Since active switches can be simultaneously operated in the boost and asymmetrical half-bridge converters, the active switches are reduced when compared to a conventional two-stage AC/DC converter. The system analysis and design considerations of the proposed converter are analyzed and discussed in detail. Finally, experiments conducted on a 240W prototype circuit are provided to verify the performance and effectiveness of the proposed converter.

\section{ACKNOWLEDGMENT}

This paper is supported by the National Science Council of Taiwan under Grant NSC99-2221-E-224-083-MY2.

\section{REFERENCES}

[1] Y.-C. Kim, L. Jin, J.-M. Lee and J.-H. Choi, "Direct digital control of single-phase ac/dc pwm converter system," Journal of Power Electronics, Vol. 10, No. 5, pp. 518-527, Sep. 2010.

[2] L. Huber, G. Liu, and M. M. Jovanovic, “Design-oriented analysis and performance evaluation of buck PFC front end,” IEEE Trans. Power Electron., Vol. 25, No. 1, pp. 85-94, Jan. 2010.

[3] T. Nussbaumer, K. Raggl, and J. W. Kolar, "Design guidelines for interleaved single-phase boost PFC circuits," IEEE Trans. Ind. Electron., Vol. 56, No. 7, pp. 2559-2573, Jul. 2009.

[4] E. H. Ismail, A. J. Sabzali, and M. A. Al-Saffar, "Buck-boost-type unity power factor rectifier with extended voltage conversion ratio," IEEE Trans. Ind. Electron., Vol. 55, No. 3, pp. 1123-1132, Mar. 2008.

[5] O. Carcia, J. A. Cobos, R. Prieto, P. Alou, and J. Uceda, "Single Phase Power Factor Correction: A Survey," IEEE Trans. Power Electron., Vol. 18, No. 3, pp. 749-755, May 2003.

[6] G. K. Andersen and F. Blaabjerg, "Current programmed control of a single-phase two-switch buck-boost power factor correction circuit,” IEEE Trans. Ind. Electron., Vol. 52, No. 1, pp. 263-271,Feb. 2005.

[7] C. A. Gallo, F. L. Tofoli, and J. A. C. Pinto, "Two-stage isolated switch-mode power supply with high efficiency and high input power factor," IEEE Trans. Ind. Electron., Vol. 57, No. 11, pp. 3754-3766, Nov. 2010.

[8] X.-S. Pu, T.-H. Nguyen, D.-C. Lee, and S.-G. Lee, "Identification of DC-link capacitance for single-phase AC/DC PWM converters," Journal of Power Electronics, Vol.10, No.3, pp. 270-276, May 2010.

[9] M. Jabbari and H. Farzanehfard, "A new soft switching step-down/up converter with inherent PFC performance," Journal of Power Electronics, Vol. 9, No. 6, pp. 835-844, Nov. 2009.

[10] L. Huber, Y. Jang, and M. M. Jovanovic, "Performance evaluation of bridgeless PFC boost rectifier," IEEE Trans. Power Electron., Vol. 23, No. 3, pp. 1381-1390, May 2008.

[11] Y. M. Liu and L. K. Chang, "Single-stage soft-switching AC-DC converter with input-current shaping for universal line applications,” IEEE Trans. Ind. Electron., Vol. 56, No. 2, pp. 467-479, Feb. 2009.

[12] K.-T. Kim, W.-Y. Choi, J.-M. Kwon, and B.-H. Kwon, “A single-stage AC/DC converter with low voltage stresses and reduced switching losses," Journal of Power Electronics, Vol. 9, No. 6, pp. 823-834, Nov. 2009.

[13] J. J. Lee, J. M. Kwon, E. H. Kim, W. Y. Choi, and B. H. Kwon, "Single-stage single-switch PFC flyback converter using a synchronous rectifier," IEEE Trans. Ind. Electron., Vol. 55, No. 3, pp. 1352-1365, Mar. 2008.

[14] R. D. O. Brioschi and J. L. F. Vieira, "High power factor electronic ballast with constant dc-link voltage,” IEEE Trans. Power Electron., Vol. 13, No. 6, pp. 1030-1037, Nov. 1998.

[15] J. Ribas, J. M. Alonso, A. J. Calleja, E. L. Corominas, M. Rico-Secade, and J. Cardesin, "Low-cost single-stage electronic ballast based on a self-oscillating resonant inverter integrated with a buck-boost PFC circuit," IEEE Trans. Ind. Electron., Vol. 48, No. 6, pp. 1196-1204, 2001.

[16] J. M. Alonso, A. J. Calleja, J. Ribas, E. L. Corominas, and M. Rico-Secade, “Analysis and design of a novel single-stage high-power-factor electronic ballast based on integrated buck half-bridge resonant inverter," IEEE Trans. Power Electron., Vol. 19, No. 2, pp. 550-559, 2004. 


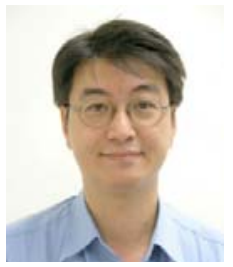

Bor-Ren Lin received his B.S. in Electronic Engineering from the National Taiwan University of Science and Technology, Taipei, Taiwan, in 1988, and his M.S. and Ph.D. in Electrical Engineering from the University of Missouri, USA, in 1990 and 1993, respectively. From 1991 to 1993, he was a Research Assistant with the Power Electronic Research Center, University of Missouri, USA. Since 1993, he has been with the Department of Electrical Engineering, National Yunlin University of Science and Technology, Douliou, Taiwan, where he is currently a Professor. He has authored and published more than 200 technical journal papers in the area of power electronics. His main research interests include power-factor correction, multilevel converters, active power filters, and soft-switching converters. Dr. Lin is an Associate Editor of the IEEE Transactions on Industrial Electronics and The Institution of Engineering and Technology Proceedings-Power Electronics. He was the recipient of Research Excellence Awards in 2004, 2005, 2007 and 2011 from the College of Engineering, National Yunlin University of Science and Technology. He received best paper awards from the IEEE Conference on Industrial Electronics and Applications 2007 and 2011, from the Taiwan Power Electronics 2007 Conference, and from the IEEE Power Electronics and Drive Systems 2009 Conference.

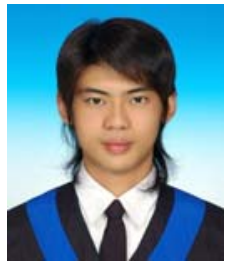

Shih-Chuan Huang is currently working toward his M.S. in Electrical Engineering at the National Yunlin University of Science and Technology, Yunlin, Taiwan. His research interests include the design and analysis of power factor correction techniques, switching mode power supplies and soft switching converters. 